Revista Colombiana de Obstetricia y Ginecología Vol. 57 N 0.4 • 2006 • (301-304)

Serie de Casos

\title{
MANEJO DEL FACTOR M ASCULINO LEVE A MODERADO CON L-CARNITINA. SERIE DE CASOS
}

\section{Managing mild to moderate male factor with L-carnitine, Case series}

Linda Mlayes, M.D. ${ }^{*}$, Felipe Vergara, M.D. ${ }^{*}$, Luis D e la H oz, M.D.*, Alfredo Gómez, M.D. ${ }^{*}$ Irmgard Amaya, Bióloga**, Maria del Carmen Vélez, Bióloga**, Guido Parra, M.D. ${ }^{* * *}$

Recibido: agosto 16/06 - Revisado: noviembre 7/06 - Aceptado: noviembre 24/06

\section{RESUMEN}

Objetivo: determinar la utilidad de la L-carnitina vía intramuscular de $1 \mathrm{gr}$ como tratamiento para los casos de factor masculino leve a moderado.

Materiales y métodos: participaron en el estudio doce sujetos a las cuales se les diagnosticó oligo- asteno-teratozospermia leve a moderada. Se les administró a un grupo L-cartinina a dosis de $1 \mathrm{gr} \mathrm{IM}$ cada 4 días por lo menos por 2 meses previo al procedimiento de reproducción asistida al que fueron sometidos junto con sus parejas. Tomamos como control los parámetros espermáticos el día en que se les realizaba el procedimiento.

Resultados: en el grupo que utilizó L-carnitina se observó una mejoría significativa al momento de realizar el procedimiento de reproducción asistida en cuanto a los parámetros espermáticos de concentración y en la movilidad, logrando embarazo en un $50 \%$.

Ginecoobstetra, Instituto de Reproducción H umana PROCREAR Barranquilla, Correo electrónico: Imlayes@ hotmail.com.

** Bióloga. Laboratorio In - Vitro, Instituto de Reproducción H umana PROCREAR, Barranquilla

*** Director Científico, Ginecoobstetra, Instituto de Reproducción H umana PROCREAR, Barranquilla.
Conclusión: el uso de L-carnitina incrementa la concentración y la movilidad de los espermatozoides, mejorando la tasa de embarazo.

Palabras clave: factor masculino, infertilidad, L-carnitina.

\section{SUMMARY}

Objective: determining the efficacy of $1 \mathrm{gr}$ of Lcarnitine applied via intramuscular route in treating mild to moderate male factor.

M aterials and methods: 12 men diagnosed as having mild to moderate oligo-astenoteratozospermia participated in the study. 0 ne group used $1 \mathrm{gr}$ I M L-carnitine every 4 days for at least 2 months prior to the assisted reproductive procedure (with their partners). The spermatic parameters obtained on the day of the procedure were taken as a control.

Results: the group which used L-carnitine for an average of 2 months showed asignificant improvement in sperm concentration and mobility at the time of the assisted procedure, pregnancy being achieved in $50 \%$ of assisted reproduction cases.

Conclusion: using L-carnitine improves sperm concentration and mobility, thereby improving pregnancy rate.

Key words: male factor, L-carnitine, infertility. 


\section{INTRODUCCIÓN}

A nivel del aparato reproductor masculino, el plasma seminal es un medio rico y complejo. Sirve a la vez de vehículo y de medio nutritivo y protector de los espermatozoides, se encuentra constituido por minerales, esteroides, glúcidos, lípidos, prostaglandinas, actividad enzimática y por componentes como la L-carnitina. Este es un cofactor requerido para la transformación de la cadena larga de ácidos grasos libres en la mitocondria para su metabolismo, realizando aś la beta oxidación para la producción de energía celular y comportándose a su vez como antioxidante a nivel del espermatozoide.

Los niveles más elevados de L-carnitina se encuentran a nivel del epidídimo, donde estas concentraciones son mucho más elevadas que en la sangre. ${ }^{1}$ Los niveles seminales bajos de carnitina y acetil-carnitina pueden ser la causa de infertilidad masculina. ${ }^{2}$

Se ha informado de una mejoría en los parámetros espermáticos principalmente en la motilidad posterior al uso de carnitinas en estudios clínicos no aleatorizados. ${ }^{3}$ Sin embargo, no han sido realizados estudio a nivel local en este sentido.

Teniendo en cuenta todo lo anterior, el objetivo de este trabajo es evaluar la posible utilidad del trata miento con L-carnitina vía intramuscular, ampollas de $1 \mathrm{gr}$ ante la presencia de un factor masculino leve a moderado.

\section{MATERIALES Y MÉTODOS}

Diseño: cohorte prospectiva de 12 hombres con edades de 20 a 40 años y diagnóstico de factor masculino como causa de su infertilidad, quienes consultaron al Centro de Reproducción Humana, PROCREAR, centro de referencia ubicado en la ciudad de Barranquilla, localizada en la región de la costa caribe en Colombia, durante el periodo de enero de 2005 hasta enero de 2006. Se incluyeron pacientes con los siguientes parámetros espermáticos: concentración espermática: 10-20 × $10^{6}$ células por mililitro, movilidad A+B: $<50 \%$, pacientes que ingresaron al programa de inseminación artifi- cial por primera vez, sin tratamientos previos realizados y con duración de la fertilidad mayor a un año. Se excluyeron aquellos pacientes recién operados de varicocele o con diagnóstico del mismo.

Tipo de muestreo: el muestreo se realizó por conveniencia, los hombres participantes fueron reclutados secuencialmente.

Procedimiento: en primera instancia se presentó al comité de bioética de la institución el cual aprobó la realización del trabajo con previa autorización del paciente por medio de un consentimiento informado que explicaba la manera de uso de la L - carnitina yla experiencia con ella. Al firmar el consentimiento el paciente iniciaba el uso de la L-carnitina ampollas intramusculares de $1 \mathrm{gr}$ cada 4 días, por lo menos por 2 meses previo a realizar la inseminación. Se esperó 14 días luego del procedimiento para confirmar el embarazo, si este era positivo cuatro semanas más tarde se confirmaba por ecografía. Se realizó control de los parámetros espermáticos el día de la inseminación intrauterina.

El tratamiento concomitante de la pareja se inició mediante la estimulación de la ovulación a la mujer con citrato de clomifeno $100 \mathrm{mg}$, el día tercero del ciclo por cinco días, siempre y cuando la ecografía basal no reportara presencia de quistes ováricos residuales, día por medio iniciando simultáneamente con el citrato de clomifeno se aplicaba una ampollade gonadotropina menopáusica humana (H MG) 75 U I y se realizaba ecografía el día 9 valorando el tamaño folicular, cantidad y grosor endometrial. Si presentaba más de tres folículos en total mayores de $16 \mathrm{~mm}$ el día 9 se cancelaba. Entre el día 11 y 12 del ciclo se inducía la ovulación con hCG 5.000 UI y 36 horas posterior a la aplicación se realizaba inseminación única por ciclo. Se tomaron como parámetros espermáticos los obtenidos en el espermograma inicial y se compararon con los obtenidos en la muestra del día de la inseminación. Se espero 14 días posterior al procedimiento para confirmar el embarazo.

Como desenlaces se midieron los parámetros espermáticos obtenidos en el espermogramainicial yse compararon con los obtenidos en la muestradel díade 
la inseminación. Así como el número de embarazos. Análisis: para el análisis descriptivo del estudio se utilizaron las medidas habituales de tendencia central y de dispersión.

\section{RESULTADOS}

En el grupo total el promedio de edad fue de 36 años, con rango de 20 a 40 años. En el grupo que recibió tratamiento médico con $\mathrm{L}$-cartinina dos meses previos a realizar lainseminación se contó con un total de 12 pacientes y la concentración inicial de espermatozoides en promedio fue de 34,3 x 106 y movilidad A + B en promedio de $49,95 \%$, en este grupo encontramos una tendencia a incrementar su concentración y movilidad tipo $A+B$, obteniendo mejor tasa de embarazo y de aborto. (Tabla 1)

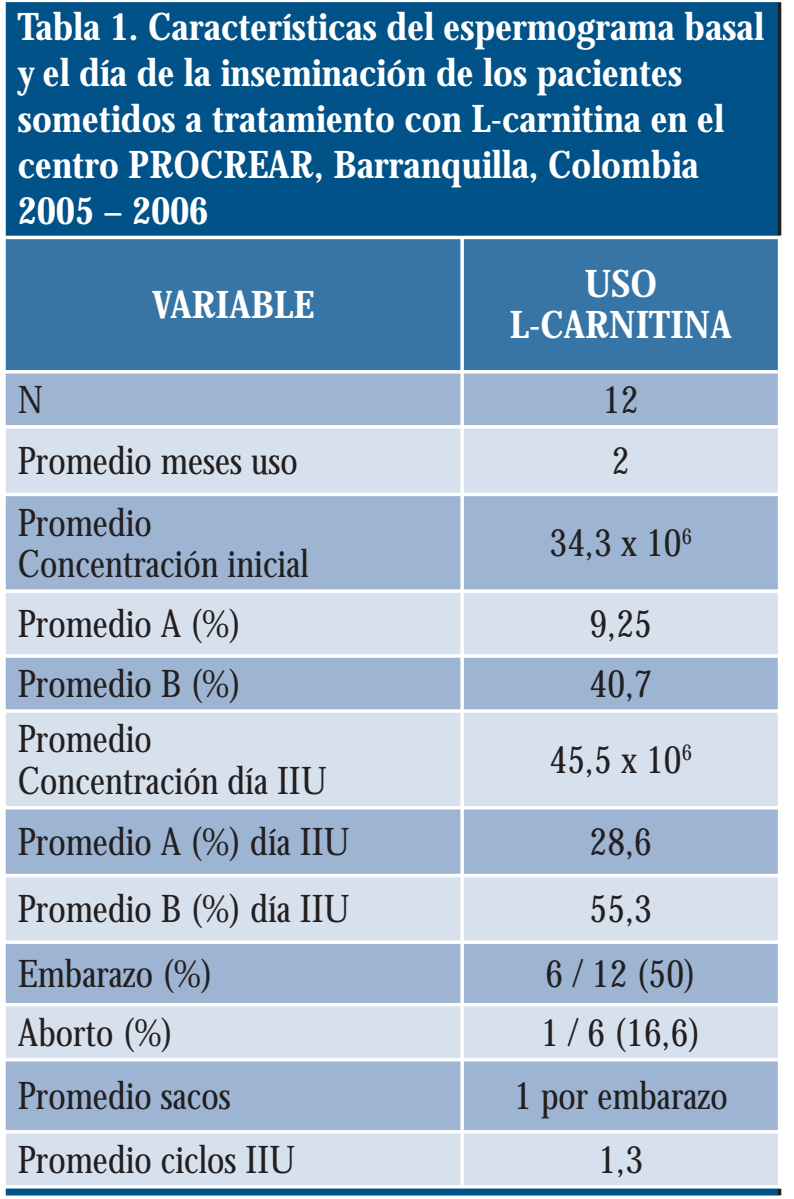

IIU : Inseminación Intrauterina

1. Aborto de saco único con cariotipo 46XY q - 6p

* 4 embarazos con sacos únicos, un embarazo con embarazo doble y uno con triple.

\section{DISCUSIÓN}

En el semen podemos encontrar células redondas las cuales representan a las células provenientes de la línea germinal como a las células de la línea leucocitaria (neutrófilos), células epiteliales, bacterias y detritus. La presencia de 2.000 .000 más de células blancas por $\mathrm{mm}$ de semen, actividad peroxidasa positiva asociada 0 no al diagnóstico de infecciones en las glándulas accesorias, conllevaa cambiosimportantes tanto bioquímicos como biológicos en el plasma seminal afectando la fertilización in vivo e in vitro. Estas células al ser activadas producen altas concentraciones de especies reactivas de oxígeno (ROS) las cuales afectan la composición de los ácidos grasos esenciales de la membrana espermática, lo cual genera una dismunición del ATP causando peroxidación lipídica, que en el hombre se encuentra regulada por enzimas antioxidantes, manifestándose con pérdida de la movilidad y viabilidad, así como alterando la capacidad de reconocimiento de los receptores del ovocito y por consiguiente su fertilización. Los ROS pueden producir el entrecruzamiento de la cromatina, cambios en la secuencia bases del ADN y rupturas. ${ }^{2}$

Se sabe que la capacitación, reacción acrosómica, hiperactivación y la unión de la zona pelúcida son mediadas por el peróxido de hidrógeno y el anillo de superóxido, sugiriendo que estos factores oxidativos pueden ser mediadores fisiológicos del proceso de fertilización. ${ }^{4}$

En el tracto reproductivo existe un número importante de enzimas que se encargan de prevenir los daños oxidativos, en especial en el epidídimo, lugar de síntesis y secreción de grandes cantidades de superóxido dismutasa extracelular (eSD 0), aunque no es el único sitio, también se produce a nivel prostático. A nivel del plasma seminal humano se han hallado cuatro enzimas que se consideran potencialmente protectoras de los espermatozoides debido a la capacidad que tienen para controlar el estrés oxidativo y son la glutation peroxidasa (GPX), glutation reductasa (GRD), superóxido dismutasa (SOD) y las que tienen actividad similar a las catalasas. M ientras las glándulas accesorias contienen 
ácido cítrico, glicerol, fosfocolina y L-carnitina las cuales se van a ver disminuidas al presentar alguna alteración a nivel de su función y se manifiesta en la composición del plasma seminal. ${ }^{5}$

Debido a que el estrés oxidativo es considerado como una las principales causas de infertilidad masculina y los efectos de la L - carnitina como antioxidante enzimático requeridos en la producción de la cadena larga de ácidos grasos para producir energía conllevando a la maduración del espermatozoide, a su vez en el plasma epididimal encontramos niveles elevados de L-carnitina con incremento en la movilidad de los espermatozoides y esto es debido al aumento de los niveles de L - carnitina en el lumen del epidídimo. Teniendo en cuenta lo anterior, la L-carnitina se encarga de prevenir la formación de ROS, remueve los radicales libre y protege a las células del estrés peroxidativo. A su vez ejerce función a nivel espermático brindándole energía para el uso del espermatozoide, lo cual afecta positivamente la movilización, maduración y proceso espermático, 4,6,7 Si bien no sabemos cual es la función clara de las células de Sertoli en este aspecto, estudios realizados en ratas sugieren que la influencia de carnitinas puede estar mediada en parte por la actividad de los niveles en las células de Sertoli. ${ }^{8}$

En la actualidad lo que la evidencia nos facilita por medio de los estudios aleatorizados controlados doble ciegos que comparan el tratamiento de L-carnitina en hombres con oligoastenospermia como el de Lenzi y cols., ${ }^{3}$ donde reportaron una significancia estadística en la mejoría de la movilidad y concentración espermática en el grupo que utilizó L-carnitina en comparación con el del placebo. M ientras que el estudio de Sigman y cols. ${ }^{9}$ donde comparan el uso de la L-carnitina en astenospermia idiopática no muestra una significancia estadística o clínica en la movilidad espermática o en su conteo total en los hombres con diagnóstico de astenospermia idiopática.
De manera que la influencia de la L-carnitina para el buen funcionamiento de la reproducción masculina se encuentra bien establecida, pero el mecanismo molecular por el cual las carnitinas controlan la fertilidad masculina no se encuentra claro hasta el momento.

\section{CONCLUSIÓN}

L-carnitina incrementa la concentración y movilidad, en pacientes con factor masculino de leve a moderado

\section{REFERENCIAS}

1. Vitali G, ParenteR, M elotti C. Carnitinesupplementation in human idiopathic asthenospermia:clinical results. Drugs Exp Clin Res 1995;21:157-9

2. Dockmeci D. Oxidative stress, male infertility and the role of carnitines. Folia M ed (Plovdiv) 2005;47:26-30.

3. Lenzi A, Lombardo F, Sgro P, Salacone P, Caponecchia $L$, D ondero $F$, et al. U se of carnitine therapy in selected cases of male factor infertility: a double-blind crossover trial. Fertil Steril 2003;79:292-300.

4. Agarwal A, Gupta S, Sikka S. The role of free radicals and antioxidants in reproduction. Curr O pin Obstet Gynecol 2006;18:325-32.

5. Gurbuz B, Yalti S, Ficicioglu C, Zehir K. Relationship between semen quality and seminal plasmatotal carnitine in infertile men. J O bstet Gynaecol 2003;23:653-6.

6. Lenzi A, Lombardo F, Gandini L, Dondero F. [M etabolism and actino of $L$-carnitine: its posible role in sperm tail function]. Arch Ital U rol N efrol Androl 1998;64:187-96.

7. Nq CM, Blackman MR, Wang C, Swerdloff RS. The role of carnitine in the male reproductive system. Ann N Y Acad Sci 2004;1033:177-88.

8. Caviglia D, Scarabelli L, Palmero S. Effects of carnitines on rat sertoli cell protein metabolism. H orm M etab Res 2004;36:221-5.

9. Sigman M, Glass S, Campagnone J, Pryor J. Carnitine for the treatment of idiopathic astenospermia: a randomized, double-blind, placebo-controlled trial. Fertil Steril 2006;85:1409-14.

\section{Conflicto de intereses: ninguno declarado.}

